\title{
Streptanoate, a new anticancer butanoate from Streptomyces sp. DC3
}

\author{
Saisattha Noomnual ${ }^{1}$, Nopporn Thasana ${ }^{2,3}$, Pareenart Sungkeeree ${ }^{4}$, Skorn Mongkolsuk ${ }^{4,5,6}$ \\ and Suvit Loprasert ${ }^{4,5,6}$
}

The Journal of Antibiotics (2016) 69, 124-127; doi:10.1038/ja.2015.95; published online 16 September 2015

Infectious diseases are still a global problem because of the steady increase in the number of microorganisms resistant to current antimicrobial agents as well as the occurrence of new emerging infectious microorganisms. ${ }^{1}$ Improvements in antimicrobial agents have been driven by concerns on safety and efficacy in terms of improved pharmacodynamics, which includes better adsorption, distribution and activity against a wide range of microorganisms, and less serious side effects. The general mechanisms of action of antimicrobial agents are inhibition of cell wall and cytoplasmic membrane synthesis, disruption of cell membrane permeability, inhibition of protein synthesis, inhibition of nucleic acid synthesis and inhibition of electron transport systems. ${ }^{2}$

Cancer is a leading cause of death in the world. Although there are effective drugs for the treatment of some cancers, these drugs often have significant side effects (that is, hair loss, anemia, immune suppression), and target cells can develop resistance. There is, therefore, a need for novel, effective and low-toxicity anticancer agents to be developed. There are a few scientific reports describing the isolation of antimicrobial compounds from various sources in Thailand. We set out to identify new bioactive compound(s) from Streptomyces sp. isolated from soil collected in Bangkok, Thailand. A new strain, Streptomyces sp. DC3, was isolated and found to produce a novel bioactive compound designated as streptanoate (1) (Figure 1).

Streptomyces sp. DC3 was isolated from a soil sample collected from Bangkok, Thailand by spreading on actinomyces isolation agar from Difco, Becton, Dickinson and Company, Franklin Lakes, NJ, USA consisting of $0.01 \%$ asparagine, $0.05 \%$ dipotassium phosphate, $0.0001 \%$ ferrous sulfate, $0.01 \%$ magnesium sulfate, $0.2 \%$ sodium caseinate, $0.4 \%$ sodium propionate and $1.5 \%$ agar and incubated at $28^{\circ} \mathrm{C}$ for $7-14$ days. Gram-staining and $16 \mathrm{~S}$ ribosomal RNA gene amplification were performed and followed by DNA sequencing. The colony morphology of Streptomyces DC3 on mannitol soya agar consisting of $2 \%$ soya flour, $2 \%$ mannitol and $1.5 \%$ agar showed round, dry and gray-green-white spores. The reverse side colony colouration is yellow-brown. Spore chain and spore morphology was determined by observation of a fully matured culture under microscope. Streptomyces DC3 is a gram-positive high GC content organism and appeared as long, rod-shaped filamentous. The spore-bearing aerial hyphae were in a simple category called flexibilis, which is a bit curled. The spores are round-shaped with smooth surface. PCR amplification of the 16S rRNA gene with the universal primers of BT3369 (5'-GGCGTGCTTAACACATGCAAGTC-3') and BT3370 $\left(5^{\prime}\right.$-TACCTTGTTACGACTTCGTCCCAA-3') resulted in a 1512-bp product. $^{3}$ The $16 \mathrm{~S}$ rRNA gene sequence showed high similarity to members of Streptomyces. Based on morphological characteristics and $16 \mathrm{~S}$ rRNA gene sequence analysis, the bacterium was identified and designated as Streptomyces sp. DC3. An isolated colony of DC3 was used to inoculate eight flasks ( $1000 \mathrm{ml}$ in size) each containing $200 \mathrm{ml}$ of mannitol soya broth consisting of $2 \%$ soya flour and $2 \%$ mannitol; the flasks were then incubated at $28^{\circ} \mathrm{C}$ with 180 r.p.m. shaking for 25 days. The cell-free supernatant was harvested by centrifugation at 7000 r.p.m. for $20 \mathrm{~min}$ and extracted with either: hexane, dichloromethane, n-butanol or ethylacetate at a ratio of 1:1 (v/v). The crude organic solvent extracts were tested for antimicrobial activity against various microorganisms via a disk diffusion assay as previously described. ${ }^{4}$ The n-butanol crude extract $(76.9 \mathrm{mg})$ exhibited the highest inhibition against a number of gram-positive bacteria and yeasts (Table 1). Anticancer activity was also assessed using MTT and XTT assays to determine cell viability. ${ }^{5,6}$ The assays were performed using the cancer cell lines: HuCCA-1 (human cholangiocarcinoma) (Siriraj Hostpital, Thailand), A549 (human lung cancer, non-small cell) (ATCC, Manassas, VA, USA; CCL-185), Hela (human cervical carcinoma) (Chulabhorn Research Institute), Molt-3 (T-lymphoblast, acute lymphoblastic leukemia) (ATCC; CRL-1552), T47-D (hormonedependent breast cancer) (ATCC; HTB-133), HepG2 (hepatocarcinoma) (ATCC; HB-8065), MDA-MB-231 (hormone-independent breast cancer) (M.D. Anderson Cancer center, USA), HL-60 (acute promyelotic leukemia) (ATCC; CCL-240), S102 (human liver cancer)

${ }^{1}$ Environmental Toxicology Program, Chulabhorn Graduate Institute, Bangkok, Thailand; ${ }^{2}$ Chemical Biology Program, Chulabhorn Graduate Institute, Bangkok, Thailand; ${ }^{3}$ Laboratory of Medicinal Chemistry, Chulabhorn Research Institute, Bangkok. Thailand; ${ }^{4}$ Applied Biological Sciences Program, Chulabhorn Graduate Institute, Bangkok, Thailand; ${ }^{5}$ Laboratory of Biotechnology, Chulabhorn Research Institute, Bangkok, Thailand and ${ }^{6}$ Center of Excellence on Environmental Health and Toxicology, Ministry of Education, Bangkok, Thailand

Correspondence: Dr S Loprasert, Laboratory of Biotechnology, Chulabhorn Research Institute, Kamphaengphet 6 Rd., Bangkok 10210, Thailand.

E-mail: suvit@cri.or.th

Received 17 July 2014; revised 17 August 2015; accepted 21 August 2015; published online 16 September 2015 
<smiles>[B]C(C)C(OC(=O)C(O)C(C)C)C(N)=O</smiles>

Figure 1 The structure of the pure compound, streptanoate (1). The IUPAC name of the compound is 1-amino-3-methyl-1-oxobutan-2-yl-2-hydroxy-3methylbutanoate.

Table 1 Susceptibility of microorganisms to antimicrobial compounds

\begin{tabular}{lccc}
\hline & \multicolumn{3}{c}{ MIC $\left(\mu g \mathrm{ml}^{-1}\right)$} \\
\cline { 2 - 4 } Microorganisms & Positive contro/A & Crude $^{\mathrm{b}}$ & Streptanoate \\
\hline B. subtilis SSE4 & $0.18 \pm 0.02$ & $15.83 \pm 3.82$ & $4.71 \pm 1.46$ \\
B. thuringiensis BE8 & $19.00 \pm 9.64$ & $18.33 \pm 2.89$ & $7.92 \pm 1.91$ \\
B. cereus UW85 & $84.00 \pm 10.39$ & $61.67 \pm 12.58$ & $126.67 \pm 25.16$ \\
B. aerophilus CH63 & $22.00 \pm 3.46$ & $21.25 \pm 3.31$ & $>400$ \\
S. aureus BT1 & $3.00 \pm 0.75$ & $141.67 \pm 14.43$ & $193.33 \pm 11.55$ \\
M. luteus TISTR Y45 & $0.14 \pm 0.00$ & $78.33 \pm 2.89$ & $103.33 \pm 5.77$ \\
S. cerevisiae BY4741 & $2.40 \pm 0.79$ & $200.00 \pm 0.00$ & $141.67 \pm 14.43$ \\
C. albicans ATCC90028 & $0.34 \pm 0.04$ & $56.67 \pm 5.77$ & $30.00 \pm 0.00$ \\
\hline
\end{tabular}

aPositive controls are ceftriaxone and amphotericin B for gram-positive bacteria and yeast, respectively.

bn-Butanol crude extract.

(King Mongkut Hospital, Thailand) and H69AR (multidrug-resistant lung cancer) (CRL-11351ATCC). MRC-5, a normal embryonic lung cell line (ATCC; CCL-171), was used as a control. Cell lines were treated with varying concentrations of n-butanol crude extract dissolved in dimethylsulfoxide. The anticancer drugs, doxorubicin and etoposide, were used as positive controls. Interestingly, crude extract exhibited remarkably high toxicity against HuCCA-1, T47-D, H69AR, MDA-MB-231 and HL-60, with all showing lower IC $_{50}$ levels than those for the positive control drug, doxorubicin $(0.20,0.04$, $27.50,1.30,0.36$ compared with $0.85,0.15,>50,1.68,1.15 \mu \mathrm{g} \mathrm{ml}^{-1}$, respectively). They also showed relatively low toxicity against the normal human embryonic lung cell line, MRC-5 (Table 2).

The n-Butanol extract was separated by gravity sephadex LH 20 gel filtration column chromatography (GE Healthcare Lifescience, Marlborough, MA, USA) with the solvent mixture of hexane: dichloromethane: methanol at a ratio of 10: 10: $1(\mathrm{v} / \mathrm{v})$ then was eluted with $100 \%$ methanol, and twelve fractions (A-L, $10 \mathrm{ml}$ each) were collected. The major active fraction obtained was fraction $G$, which produced a white pellet after evaporation of the solvent $(9.1 \mathrm{mg})$ with $11.8 \%$ yield.

The structure of the purified bioactive compound in fraction $G$ was elucidated with $400 \mathrm{MHz}$ NMR (Bruker Biospin, Rheinstetten, Germany), APCI-TOF-MS in positive ion mode (Micro TOF, Bruker Daltonics), IR (Perkin Elmer Spectrum One, Waltham, MA, USA), and UV (UV1700 Pharma Spec Shimadzu spectrophotometer, Japan). The bioactive compound was determined to be the butanoate derivative, 1-amino-3-methyl-1-oxobutan-2-yl-2-hydroxy-3-methylbutanoate, which was designated as streptanoate (1) (Figure 1). The streptanoate (1) was obtained as white powder $[\alpha]_{\mathrm{D}}^{27}+51.8^{\circ}(\mathrm{c}, 0.1$, $\mathrm{CH}_{3} \mathrm{OH}$ ). The IR spectrum showed absorption bands for hydroxyl and amide groups $\left(\mathrm{O}-\mathrm{H}\right.$ and $\mathrm{N}-\mathrm{H}$ stretching) at $v_{\max } 3291 \mathrm{~cm}^{-1}$ and ester and amide $\left(\mathrm{C}=\mathrm{O}\right.$ stretching) at $1627 \mathrm{~cm}^{-1}$; the UV spectrum revealed the absorption band at $\lambda_{\max } 203(\log \varepsilon=6.12) \mathrm{nm}$ and
Table 2 Cytotoxicity of anticancer compounds against various cell lines

\begin{tabular}{|c|c|c|c|}
\hline \multirow[b]{2}{*}{ Cell lines } & \multicolumn{3}{|c|}{$I_{50}\left(\mu \mathrm{g} \mathrm{m} I^{-1}\right)$} \\
\hline & Positive control & Crude $^{b}$ & Streptanoate \\
\hline HuCCA-1 & $0.85 \pm 0.07$ & $0.20 \pm 0.01$ & $2.20 \pm 0.75$ \\
\hline A549 & $0.16 \pm 0.01$ & $0.18 \pm 0.00$ & $1.40 \pm 0.14$ \\
\hline Molt-3 & $0.03 \pm 0.01$ & $0.52 \pm 0.03$ & ND \\
\hline Hela & $0.07 \pm 0.01$ & $1.46 \pm 0.06$ & ND \\
\hline T47-D & $0.15 \pm 0.03$ & $0.04 \pm 0.01$ & $45.00 \pm 0.00$ \\
\hline H69AR & $>50$ & $27.50 \pm 0.07$ & ND \\
\hline HepG2 & $0.49 \pm 0.59$ & $1.20 \pm 0.59$ & $37.00 \pm 4.76$ \\
\hline S102 & $0.90 \pm 0.10$ & $15.6^{\mathrm{b}}$ & ND \\
\hline MDA-MB-231 & $1.68 \pm 0.39$ & $1.30 \pm 0.34$ & $7.67 \pm 2.08$ \\
\hline HL-60 & $1.15 \pm 0.31$ & $0.36 \pm 0.03$ & $3.85 \pm 1.06$ \\
\hline MRC-5 & $18.33^{c}$ & $25.95^{c}$ & $18.10^{c}$ \\
\hline
\end{tabular}

Abbreviation: ND, not determined.

apositive controls are doxorubicin and etoposide (only for HL-60).

bn-Butanol extract.

c\% Cytotoxicity at $50 \mu \mathrm{g} \mathrm{ml}^{-1}(86.21 \mu \mathrm{m})$ concentration.

260 ( $\log \varepsilon=5.42) \mathrm{nm}$ corresponding to the carboxylic acid derivative moiety. This compound was negative in ninhydrin test which confirmed the presence of a hydroxyl ester/amide group.

The APCI-TOF-MS (positive) of streptanoate (1) established a molecular formula of $\mathrm{C}_{10} \mathrm{H}_{20} \mathrm{NO}_{4}\left([\mathrm{M}+\mathrm{H}]^{+} \mathrm{m} / z\right.$ 218.1395, calcd 218.1387). This formula provided two degrees of unsaturation corresponding to two carbonyl groups of the ${ }^{13} \mathrm{C}$ NMR spectrum at $\delta_{\mathrm{C}} 172.5$ and 173.0 p.p.m. The proton-bearing carbons in the ${ }^{13} \mathrm{C}$ NMR spectrum were assigned by an HMQC experiment and the ${ }^{1} \mathrm{H}$ and ${ }^{13} \mathrm{C}$ correlations were shown in Table 3. The ${ }^{1} \mathrm{H}-{ }^{1} \mathrm{H}$ COSY spectrum revealed two isobutyl structures. The first partial structure showed correlation of the hydroxyl proton $\left(\delta_{\mathrm{H}}\right.$ 7.47.p.p.m.) with methine proton $\mathrm{H}-2$ ( $\delta_{\mathrm{H}} 4.30$ p.p.m.). The $\mathrm{H}-2$ proton showed correlation with H-3 $\left(\delta_{\mathrm{H}} 2.20\right.$ p.p.m.) which was also correlated with two methyl groups $\mathrm{H}-4$ and $\mathrm{H}-5$ ( $\delta_{\mathrm{H}} 0.92$ and 0.94 p.p.m.). Another partial structure also similarly showed correlations of methine proton $\mathrm{H}-2^{\prime}\left(\delta_{\mathrm{H}} 3.85\right.$ p.p.m.) to methine proton $\mathrm{H}-3^{\prime}\left(\delta_{\mathrm{H}} 2.13\right.$ p.p.m.) and $\mathrm{H}-3^{\prime}$ to two methyl groups $\mathrm{H}-4^{\prime}$ and $\mathrm{H}-5^{\prime}\left(\delta_{\mathrm{H}} 0.84\right.$ and 0.99 p.p.m.).

The connectivity of the partial structures was accomplished by an HMBC experiment and three-bond HMBC correlations were summarized in Figure 2. The HMBC correlations of methyl protons $\mathrm{H}-4$ and $\mathrm{H}-5$ with the hydroxyl methine carbon $\mathrm{C}-2\left(\delta_{\mathrm{C}} 56.0\right.$ p.p.m.) and methyl protons $\mathrm{H}-4^{\prime}$ and $\mathrm{H}-5^{\prime}$ with the methine carbon $\mathrm{C}-2^{\prime}\left(\delta_{\mathrm{C}}\right.$ 74.5 p.p.m.) confirmed two partial structures of 2-hydroxy-3methylbutanoate and 2-hydroxy-3-methylbutanamide. The connectivity of these two partial structures was determined by a key HMBC correlation of $\mathrm{H}-2^{\prime}\left(\delta_{\mathrm{H}} 3.85\right.$ p.p.m.) with C-1 ( $\delta_{\mathrm{C}} 172.5$ p.p.m.).

Streptanoate was dissolved in dimethylsulfoxide $\left(10 \mathrm{mg} \mathrm{ml}^{-1}\right.$ stock) and assayed for MIC ${ }^{7}$ against the susceptible microorganisms previously mentioned in Table 1 . The MIC value of streptanoate was less than that of the n-butanol crude extract for B. subtilis, $B$. thuringiensis, S. cerevisiae and C. albicans (Table 1). In addition, streptanoate demonstrated notable cytotoxicity against HuCCA-1, A549 and HL-60 cancer cell lines ( $\mathrm{IC}_{50} 2.2,1.4,3.8 \mu \mathrm{g} \mathrm{ml}^{-1}$, respectively) but was relatively nontoxic to the normal cell line (MRC-5), exhibiting a similar degree of cytotoxicity as the positive control drug, Doxorubicin (18.1 vs 18.3\%) (Table 2). We observed that the $\mathrm{IC}_{50}$ values for streptanoate against all tested cell lines were higher than those of crude extract suggesting that there might be more 
Table 3 The ${ }^{1} \mathrm{H}$ and ${ }^{13} \mathrm{C}$ spectral data of streptanoate (1) in DMSO- $\mathrm{d}_{6}$

\begin{tabular}{lcc}
\hline & \multicolumn{2}{c}{ Streptanoate } \\
\cline { 2 - 3 } Streptanoate & $\delta_{C}$ & $\delta_{H}[$ int, mult, J (Hz)] \\
\hline 1 & $172.5^{\mathrm{a}}$ & - \\
$1^{\prime}$ & $173.0^{\mathrm{a}}$ & - \\
2 & $56.0^{\mathrm{a}}$ & $4.30(1 \mathrm{H}, \mathrm{m})$ \\
$2^{\prime}$ & 74.5 & $3.85(1 \mathrm{H}, \mathrm{m})$ \\
3 & 29.7 & $2.20(1 \mathrm{H}, \mathrm{m})$ \\
$3^{\prime}$ & 30.3 & $2.13(1 \mathrm{H}, \mathrm{m})$ \\
$4^{\prime}$ & 16.6 & $0.92(3 \mathrm{H}, \mathrm{d}, 7.2)$ \\
$4^{\prime}$ & 14.7 & $0.84(3 \mathrm{H}, \mathrm{d}, 6.8)$ \\
5 & 18.0 & $0.94(3 \mathrm{H}, \mathrm{d}, 7.9)$ \\
$5^{\prime}$ & 18.1 & $0.99(3 \mathrm{H}, \mathrm{d}, 6.9)$ \\
OH & - & $7.47(1 \mathrm{H}, \mathrm{d}, 8.7)$ \\
\hline
\end{tabular}

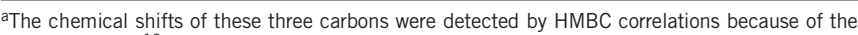
low intensity in ${ }^{13} \mathrm{C}$ NMR spectrum.

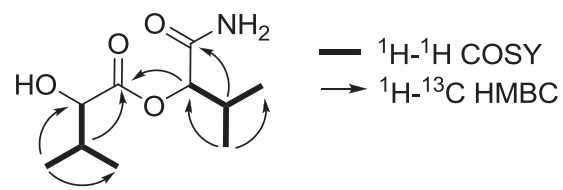

Figure 2 Selective COSY and HMBC correlations of streptanoate (1).

than one bioactive anticancer compound besides streptanoate in the crude extract. We are currently attempting to isolate more active compound(s) from this crude extract.

Streptanoate (1) is a small linear butanoate derivative, 1-amino3-methyl-1-oxobutan-2-yl-2-hydroxy-3-methylbutanoate, $\quad(\mathrm{MW}=$ 217.13) making it easier to penetrate through the cell membrane than the larger and more complex molecules like some current drugs. Furthermore, streptanoate contains functional alpha-hydroxy acid ester and amide groups that can further facilitate its entry into cell. ${ }^{8}$ To our knowledge, this is the first report of bioactive butanoate compound isolated from the species of Streptomyces. There are some previous reports describing butanoate derivatives from various sources such as bacteria, plants and chemical synthesis, which act as antimicrobial or antitumor compounds. For example, the antituberculosis agent methy4-(2-octdecylcyclopropen-1-yl) butanoate is a specific inhibitor of mycolate synthesis via obstruction of cis-tetracos-5-enoate elongase activity. The inhibition of this enzyme leads to disruption of the biosynthesis of mycolic acid, which is a structural component of the mycobacterial cell wall. ${ }^{9,10}$ An anticancer butanoate derivative, 4-(N-hydroxyphenyl) retinamide (4-HPR), was synthesized as 5-hydroxyphenyl butanoate retinamide (5-HPBR) and found to have 2- to 6-fold higher cytotoxicity than 4-HPR against various cancer cell lines. The potent inhibitory effect of 5-HPBR was suggested to be mediated by apoptosis but the exact mechanism appears to differ among cancer cell types. ${ }^{11}$ Another example of a bioactive butanoate derivative is the novel bioactive compound, 3-hydroxy, 2-methoxy-sodium butanoate, isolated from the leaves of Clerodendrum phlomidis. This compound displayed considerably potent anti-inflammatory and anti-arthritic effects. ${ }^{12}$

Furthermore, short-chain fatty acids, including butanoates, have been shown to act as histone deacetylase inhibitors. ${ }^{13}$ Sodium phenylbutyrate has undergone clinical trial studies as a cancer treatment; however, it is not an ideal agent as it requires high concentrations (millimolar) to produce an effective response. ${ }^{14}$ In general, histone deacetylase inhibitors block deacetylase enzyme activity by binding to the active site of the enzyme. The acetylation of histones promotes transcription of the tumor suppressor gene, p53, and the induction of cellular differentiation and apoptosis pathways. ${ }^{15}$ Sodium butanoate was reported to induce the transcription of $\mathrm{p} 21^{\text {WAF} 1}$ in transformed cells, which subsequently led to cell cycle arrest. This was accompanied by the accumulation of acetylated histones. ${ }^{16}$ It was also found to inhibit the growth of colorectal cancer cells. ${ }^{17}$ Further investigation is needed to determine if streptanoate-mediated cytotoxicity mirrors the mode of action of sodium butanoate.

The results reported here show that streptanoate (1) exhibits both antimicrobial and anticancer activities. The fact that this compound is relatively nontoxic to a normal human cell line, exhibiting the same level of cytotoxicity as the currently used drug doxorubicin, but possessing high cytotoxicity to cancer cell lines suggests that it is a promising candidate to be further developed as an anticancer agent. In addition, its small size, and possession of functional groups suitable for side chain alteration to enhance its water solubility and cellular uptake, make it a high-potential starting lead compound.

\section{CONFLICT OF INTEREST}

The authors declare no conflict of interest.

\section{ACKNOWLEDGEMENTS}

This research work was supported in part by a grant from the Chulabhorn Research Institute and Center of Excellence on Environmental Health and Toxicology, Thailand. We convey special thanks to Prattya Nealmongkol, Sakornrat Thorroad, Nitirat Chimnoi, Siriporn Wongbundit and Kittiporn Trisupakarn for their kind assistance with chromatography, NMR, HRMS, IR, and also to Pakamas Intachote for cytotoxicity experiments. We are grateful to James Dubbs for critical reading and discussion.

1 Okeke, I. N. et al. Antimicrobial resistance in developing countries. Part I: recent trends and current status. Lancet Infect. Dis. 5, 481-493 (2005).

2 Newton, B. A. Mechanisms of antibiotic action. Annu. Rev. Microbiol. 19, 209-240 (1965).

3 Rhee, K. H. Isolation and characterization of Streptomyces sp KH-614 producing antiVRE (vancomycin-resistant enterococci) antibiotics. J. Gen. Appl. Microbiol 48, 321-327 (2002).

4 Thasana, N. et al. Bacillus subtilis SSE4 produces subtulene A, a new lipopeptide antibiotic possessing an unusual C15 unsaturated $\beta$-amino acid. FEBS Lett. 584, 3209-3214 (2010).

5 Scudiero, D. A. et al. Evaluation of a soluble tetrazolium/formazan assay for cell growth and drug sensitivity in culture using human and other tumor cell lines. Cancer Res. 48, 4827-4833 (1988)

6 Mosmann, T. Rapid colorimetric assay for cellular growth and survival: application to proliferation and cytotoxicity assays. J. Immunol. Methods. 65, 55-63 (1983).

7 Andrews, J. M. Determination of minimum inhibitory concentrations. J. Antimicrob. Chemother. 48, 5-16 (2001).

8 Lambert, P. A. Cellular impermeability and uptake of biocides and antibiotics in grampositive bacteria and mycobacteria. J. Appl. Microbiol. 92, 46S-54S (2002).

9 Nguyen, L. N., Lopes, L. C. L., Cordero, R. J. B. \& Nosanchuk, J. D. Sodium butyrate inhibits pathogenic yeast growth and enhances the functions of macrophages. J. Antimicrob. Chemother. 66, 2573-2580 (2011).

10 Wheeler, P. R., Besra, G. S., Minnikin, D. E. \& Ratledge, C. Inhibition of mycolic acid biosynthesis in a cell-wall preparation from Mycobacterium smegmatis by methyl 4-(2octadecylcyclopropen-1-y1) butanoate, a structural analogue of a key precursor. Lett. Appl. Microbiol. 17, 33-36 (1993).

$11 \mathrm{Han}, \mathrm{H}$. S. et al. Potent effect of 5-HPBR, a butanoate derivative of 4-HPR, on cell growth and apoptosis in cancer cells. Int. J. Cancer. 109, 58-64 (2004).

12 Prakash Babu, N., Saravanan, S., Pandikumar, P., Bala Krishna, K., Karunai Raj, M. \& Ignacimuthu, S. Anti-inflammatory and anti-arthritic effects of 3-hydroxy, 2-methoxy sodium butanoate from the leaves of Clerodendrum phlomidis L.f. Inflamm. Res. 63, 127-138 (2014).

13 Newmark, H. L., Lupton, J. R. \& Young, C. W. Butyrate as a differentiating agent: pharmacokinetics, analogues and current status. Cancer Lett. 78, 1-5 (1994). 
14 Gilbert, J. et al. A phase I dose escalation and bioavailability study of oral sodium phenylbutyrate in patients with refractory solid tumor malignancies. Clin. Cancer Res. 7, 2292-2300 (2001).

15 Kouraklis, G., Misiakos, E. P. \& Theocharis, S. Histone deacetylase inhibitors as a potential therapeutic agent for human cancer treatment. Targeted Oncol. 1, 34-41 (2006).
16 Chen, Y. X., Fang, J. Y., Zhu, H. Y., Lu, R., Cheng, Z. H. \& Qiu, D. K. Histone acetylation regulates p21WAF1 expression in human colon cancer cell lines. World $\mathrm{J}$. Gastroenterol. 10, 2643-2646 (2004).

17 Kramer, O. H., Gottlicher, M. \& Heinzel, T. Histone deacetylase as a therapeutic target. Trends Endocrinol. Metab. 12, 294-300 (2001).

Supplementary Information accompanies the paper on The Journal of Antibiotics website (http://www.nature.com/ja) 